\title{
MUC1 cell surface mucin is a critical element of the mucosal barrier to infection
}

\author{
Julie L. McAuley, ${ }^{1}$ Sara K. Linden, ${ }^{1}$ Chin Wen Png, ${ }^{1}$ Rebecca M. King, ${ }^{2}$ Helen L. Pennington, ${ }^{1}$ \\ Sandra J. Gendler, ${ }^{3}$ Timothy H. Florin, ${ }^{1}$ Geoff R. Hill, ${ }^{4}$ Victoria Korolik, ${ }^{2}$ and Michael A. McGuckin ${ }^{1}$

\begin{abstract}
1Mucosal Diseases Program, Mater Medical Research Institute and The University of Queensland, South Brisbane, Queensland, Australia. 2Institute for Glycomics, Griffith University Institute for Glycomics, Gold Coast, Queensland, Australia. ${ }^{4}$ Division of Infectious Diseases and Immunology, Queensland Institute of Medical Research, Herston, Queensland, Australia.
\end{abstract} \\ 3Department of Biochemistry and Molecular Biology and Tumor Biology Program, Mayo Clinic College of Medicine, Scottsdale, Arizona, USA.
}

\begin{abstract}
Cell surface mucin glycoproteins are highly expressed by all mucosal tissues, yet their physiological role is currently unknown. We hypothesized that cell surface mucins protect mucosal cells from infection. A rapid progressive increase in gastrointestinal expression of mucin 1 (Muc1) cell surface mucin followed infection of mice with the bacterial pathogen Campylobacter jejuni. In the first week following oral infection, C. jejuni was detected in the systemic organs of the vast majority of $\mathrm{Muc1}^{-/-}$mice but never in $\mathrm{Muc1}^{1^{++}}$mice. Although C. jejuni entered gastrointestinal epithelial cells of both $\mathrm{Muc1}^{-/-}$and $\mathrm{Muc1}^{+/+}$mice, small intestinal damage as manifested by increased apoptosis and enucleated and shed villous epithelium was more common in $\mathrm{Muc1}^{-/-}$ mice. Using radiation chimeras, we determined that prevention of systemic infection in wild-type mice was due exclusively to epithelial Muc1 rather than Muc1 on hematopoietic cells. Expression of MUC1-enhanced resistance to C. jejuni cytolethal distending toxin (CDT) in vitro and CDT null C. jejuni showed lower gastric colonization in $\mathrm{Muc1}^{-/-}$mice in vivo. We believe this is the first in vivo experimental study to demonstrate that cell surface mucins are a critical component of mucosal defence and that the study provides the foundation for exploration of their contribution to epithelial infectious and inflammatory diseases.
\end{abstract}

\section{Introduction}

Penetration of mucosal barriers by microbial pathogens, subsequent damage to epithelial cells, and ensuing inflammatory responses cause both acute and chronic diseases with substantial impact on human health. Although mucins have long been regarded as involved in mucosal barrier function, there are no empirical in vivo studies, to our knowledge, clearly demonstrating a role for either cell surface or secreted mucins in host defense against infection.

Cell surface mucins are transmembrane glycoproteins expressed at the apical surface of all mucosal epithelial cells. Ten cell surface mucin genes have been identified, and multiple genes are expressed in tissues at greatest risk of infection (1). The extracellular domain of these mucins forms an extremely large thread-like structure covered by a dense array of complex O-linked oligosaccharides and can be shed from the cell surface. Most mucosal pathogens have evolved adhesins for carbohydrates present in the glycocalyx, and many adhesins bind mucin oligosaccharides (2). The cytoplasmic domains of cell surface mucins are highly conserved across species, undergo both serine and tyrosine phosphorylation, and interact with kinases and adaptor molecules (3-7), consistent with a role in signal transduction. However, the primary function of these mucins is not understood.

Mucin 1 (MUC1) is a cell surface mucin broadly expressed in mucosal tissues (8). Consistent with a role in host defense, mucosal epithelial cells transfected with MUC1 are less susceptible to viral invasion

Nonstandard abbreviations used: CDT, cytolethal distending toxin; $\triangle \mathrm{CDT}-\mathrm{B}$, chloramphenicol-resistant isogenic mutant of C. jejuni strain 81-176 lacking the CDT-B gene; Le ${ }^{\mathrm{b}}$, Lewis-b; Muc1, mucin 1; shRNA, short-hairpin RNA; sialyl-Le ${ }^{\mathrm{x}}$, sialyl-Lewis-x.

Conflict of interest: The authors have declared that no conflict of interest exists. Citation for this article: J. Clin. Invest. 117:2313-2324 (2007). doi:10.1172/JCI26705. in vitro $(9,10)$, and $\mathrm{Muc1}^{-1-}$ mice in conventional housing develop bacterial conjunctivitis and chronic infection of the reproductive tract $(11,12)$. The respiratory pathogen Pseudomonas aeruginosa binds MUC1, inducing phosphorylation of the cytoplasmic domain (4), demonstrating that MUC1 signals in response to bacteria. MUC1 interacts with growth factor receptors (13) and inhibits the intrinsic pathway of apoptosis (14-16), which suggests that MUC1 modulates a critical balance between growth to maintain barrier function and apoptosis to dispose of infected cells in mucosal epithelia.

We hypothesize that cell surface mucins act as releasable decoy molecules, displaying an array of targets for microbial adhesion, thereby limiting binding of pathogens to other molecules in the glycocalyx. Furthermore, we contend that following release of the extracellular subunit, the cytoplasmic subunit is involved in ensuring appropriate activation, proliferation, or apoptotic responses to microbes that have penetrated overlying mucus. Although Campylobacter jejuni infection is a major cause of gastroenteritis, its mechanisms of pathogenicity are poorly understood. C. jejuni is highly motile within secreted mucus, is chemoattracted toward mucins, and binds to mucin oligosaccharide structures $(17,18)$, making it an ideal model pathogen for exploration of cell surface mucin function in vivo. In this study, using C. jejuni infection and $\mathrm{Mucl}^{-/}$ mice, we clearly demonstrate in vivo the critical importance of Muc1 in limiting mucosal infection and show that MUC1-expressing intestinal cells have increased resistance to the C. jejuni genotoxin, cytolethal distending toxin (CDT).

\section{Results}

Gastrointestinal expression of Muc1 alters rapidly in response to infection. Goblet cell hyperplasia and increased release of secreted mucins are well-characterized responses to mucosal infection. In comparison, little is known of regulation of cell surface mucins in response 
to infection. Therefore, we determined expression of Muc1 within gastrointestinal tissues of mice orally infected with the bacterial pathogen C. jejuni (see Figure 1 and Supplemental Figure 1; supplemental material available online with this article; doi:10.1172/ JCI26705DS1). In the normal stomach, Muc1 was present on the apical membrane surface of cells deep within gastric pits and on the surface epithelium. Moderate intensity cytoplasmic staining was observed in cells of the fundic and cardiac glands, weak cytoplasmic staining in mucus cells of the surface epithelium, and only very weak staining of secreted material. In comparison, in the small intestine, cecum, and large intestine, only very weak occasional Muc1 staining was seen.

Following infection, there was a rapid increase in the proportion of cells that were positive and the staining intensity of Muc1 (see Figure 1 and Supplemental Figure 1). In the stomach, an increase in cell surface and cytoplasmic Muc1 was seen at the luminal surface beginning 2 hours after inoculation and peaking 1-2 days later. Muc1 also was detected by immunohistochemistry in luminal secretions in infected mice, consistent with direct secretion or shedding of this mucin in response to infection. In the small intestine, there was a strong induction of Muc1 expression restricted to isolated clusters of cells within the villous epithelium 2-24 hours following infection (see Figure 1 and Supplemental Figure 1). Sites where epithelial cells appeared to have been shed or enucleated were seen in 1 of 4,1 of 4 , and 3 of 4 mice at 2, 6, and 24 hours, respectively. At 6 and 24 hours, all of these sites showed more than $75 \%$ of cells expressing Muc1, with staining intensity scored at 2 or 3. Damage and foci of intense Muc1 staining were not seen in uninfected mice. In the cecum and large intestine, cytoplasmic staining of surface epithelial cells increased substantially beginning 6 hours after infection and was maintained for 2 days (see Figure 1 and Supplemental Figure 1).

C. jejuni adheres to murine mucins. A limited number of studies have investigated C. jejuni adherence to and chemotaxis toward mucins $(17,18)$. However, there are no published studies regarding murine intestinal mucins, and mucin oligosaccharides can vary between species. We now demonstrate adherence of C. jejuni to the murine small intestinal secreted mucin, Muc2. Importantly, binding to Muc2 was influenced by $\mathrm{pH}$, with binding highest at intestinal $\mathrm{pH}$ 5.5-6.0 (see Figure 2, A and B). Desialylation of mucin with neuraminidase enhanced binding of C. jejuni and eliminated the influence of $\mathrm{pH}$ (see Figure 2B). These data suggest there are at least 2 different mucin oligosaccharide ligands for $C$. jejuni on murine mucin: a sialylated oligosaccharide bound by a $\mathrm{pH}$-influenced adhesin and a nonsialylated structure bound by a $\mathrm{pH}$-independent adhesin. We used synthetic oligosaccharides conjugated to human serum albumin to show negligible binding of C. jejuni to the Lewis-b (Le $\left.{ }^{b}\right)$ and sialyl-Lewis-x (sialyl-Le ${ }^{\mathrm{x}}$ ) structures bound by the related mucinbinding bacteria Helicobacter pylori and strong binding to the $\mathrm{H}$ type 2 structure present on gastrointestinal mucins (see Figure 2C). We stably transfected MUC1 into human intestinal HCT116 cells, which normally express very low levels of MUC1 (Figure 2D). Confluent HCT116 cells were cocultured with C. jejuni under microaerophilic conditions to provide a more physiological environment for the bacteria (19). The expression of MUC1 promoted more rapid adherence of bacteria but had no influence on later adhesion nor the degree of invasion of the epithelial cells (Figure 2D).

Systemic infection with C. jejuni occurs rapidly in $\mathrm{Muc1}^{-1-}$ mice. The increased expression of Muc1 in response to C. jejuni infection showed that Muc1 is part of an early epithelial response to infec-

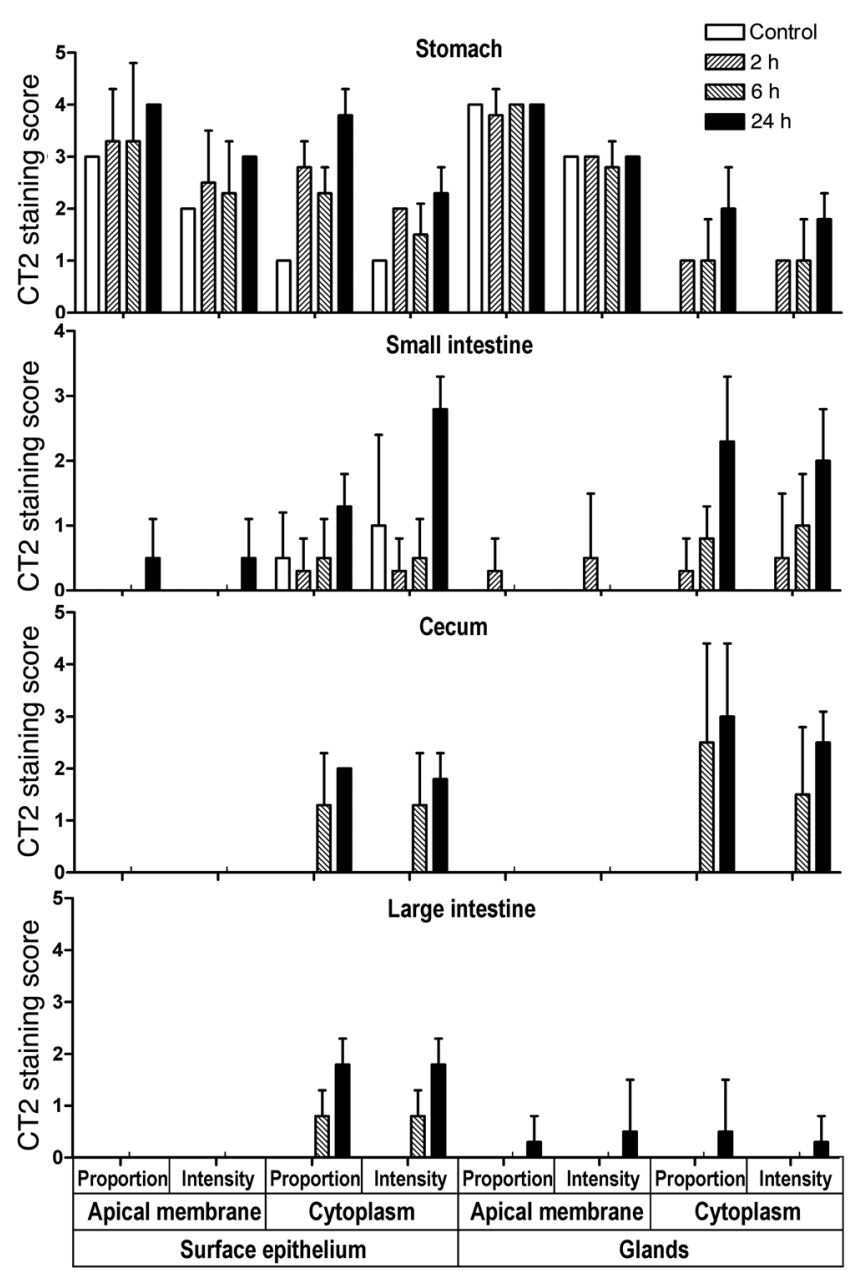

Figure 1

Gastrointestinal expression of Muc1 is rapidly upregulated in response to infection with $C$. jejuni. Muc1 expression was determined by immunohistochemistry with the CT2 cytoplasmic domain antibody in the stomach, small intestine, and large intestine of uninfected $\mathrm{Muc1}^{+/+}$ mice (control) and mice infected with $10^{4} \mathrm{C}$. jejuni for 2,6 , and 24 hours. Scoring of the proportion of cells staining and the staining intensity for deep glands or the surface epithelium (villous epithelium in the small intestine) was performed blind to treatment. Examples of staining at each time point are provided in Supplemental Figure 1. No staining was seen in uninfected or infected $\mathrm{Muc1}^{-/-}$mice.

tion. To ascertain the significance of Muc1 for host defense in vivo, we challenged $\mathrm{Muc1}^{1^{-/}}$and $\mathrm{Muc1}^{+/+}$mice with C. jejuni. In a series of experiments, oral inoculation with $10^{2}-10^{8}$ C. jejuni resulted in colonization of the gastrointestinal tract of the majority of both $\mathrm{Muc1}^{+/+}$ (50 of 68, 71\%) and $\mathrm{Muc1}^{-/-}$(64 of 68, 94\%) mice assessed 2 hours to 6 days following infection. Demonstrating that Muc1 is a critical component of the gastrointestinal barrier to infection by this pathogen, C. jejuni was cultured from at least 1 systemic organ (liver, lungs, or spleen) of 53 out of 68 (78\%) $\mathrm{Muc}^{-/-}$mice in striking contrast to 0 of $68 \mathrm{Muc1}^{+/+}$mice. In the experiment shown in Figure $3 \mathrm{~A}\left(6\right.$ days, $10^{8} \mathrm{C}$. jejuni), while levels of colonization were equivalent in small and large intestines of $\mathrm{Muc1}^{+/+}$and $\mathrm{Muc1}^{-/-}$mice, levels of colonization were significantly higher in stomachs of $\mathrm{Muc1}^{-/-}$mice, and C. jejuni was cultured from livers ( 6 of 6 mice), lungs (4 of 6 ), and spleens ( 2 of 6 ) of $\mathrm{Muc1}^{-/-}$mice but not from systemic tissues of any $\mathrm{Mucl}^{+/+}$mice. 
A

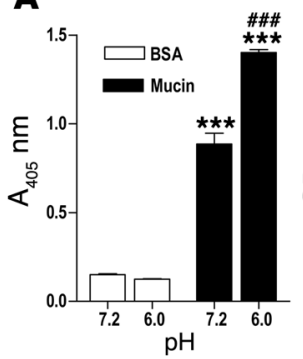

B

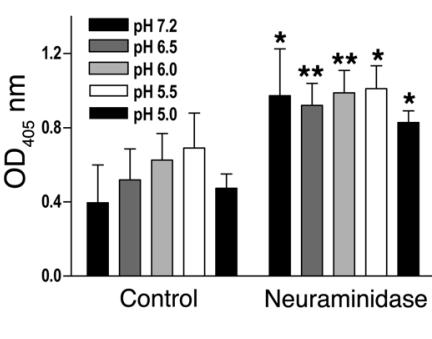

C

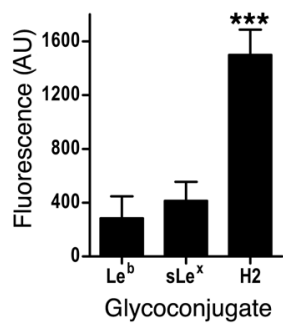

D
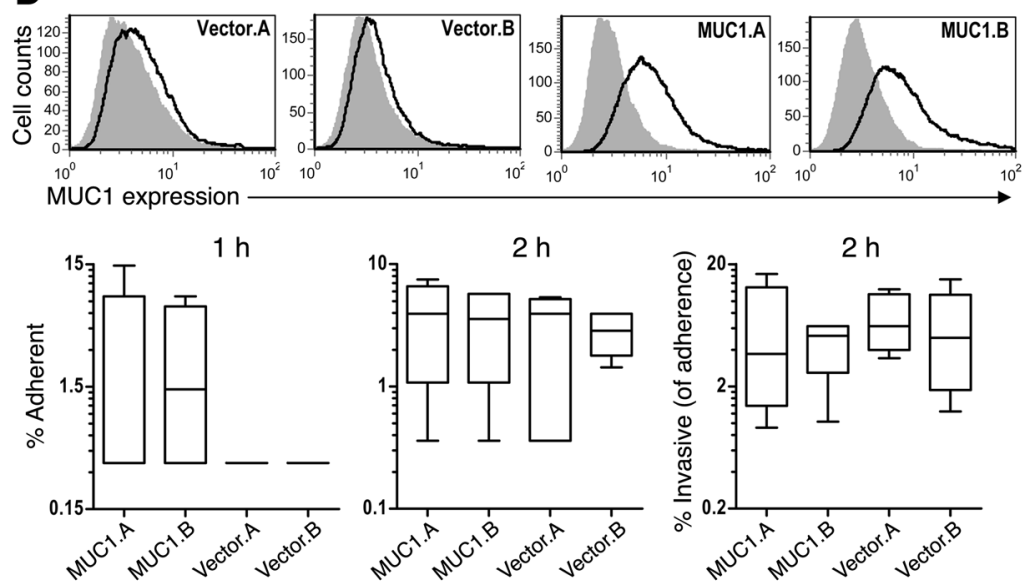

Figure 2

C. jejuni adheres to murine intestinal mucins and the $\mathrm{H}$ type 2 oligosaccharide and binds more rapidly to MUC1expressing cells. ELISA results showing (A) binding of C. jejuni strain 81116 to mucin purified from murine small intestine and BSA (control for nonspecific binding) at $\mathrm{pH} 7.2$ and 6.0 and (B) binding at $\mathrm{pH} 7.2-5.0$ both without (control) and with prior desialylation of mucin with neuraminidase. (C) Binding of mucin oligosaccharides conjugated to FITC-labeled human serum albumin to $C$. jejuni. Fluorescence units are shown after deducting mean background autofluorescence of the $C$. jejuni alone. sLex, sialyl-Le ${ }^{x} ; \mathrm{H} 2, \mathrm{H}$ type 2. (D) MUC1 expression determined by flow cytometry in 2 independent stable clones established from HCT116 intestinal cancer cells transfected with MUC1 (MUC1.A and MUC1.B) and 2 independent stable clones from the pcDNA3 vector (Vector.A and Vector.B) (shaded area is negative control antibody; dark line is $\mathrm{BC} 2$ antibody reactive with the extracellular domain of MUC1). Clones were cocultured with $10^{6} \mathrm{C}$. jejuni per well for 1 or 2 hours under microaerophilic conditions. Adhesion of $C$. jejuni was determined at 1 and 2 hours, and invasion was determined at 2 hours only. Mean \pm SD is shown. (A) ${ }^{* \star *} P<0.001$ versus BSA; \#\#\# $P<0.001$ versus $\mathrm{pH} 7.2$; (B) ${ }^{*} P<0.05 ;{ }^{* *} P<0.01$ versus control; $(\mathbf{C}){ }^{* * *} P<0.001$ versus albumin-FITC; ANOVA and Tukey's post-hoc test were used. (D) Box plots showing medians, quartiles, and ranges are shown.
The experiment shown in Figure 3B (4 days, $10^{6}$ to $10^{2}$ bacteria) demonstrates that $C$. jejuni crosses the gastrointestinal barrier in $M u c 1^{-/-}$mice at inoculation doses as low as $10^{2}$ bacteria. Even at this very low dose, all $M u c 1^{-/-}$mice developed systemic infection compared with no detectable systemic organ infection in any $\mathrm{Mucl}^{+/+}$mice. Colonization levels of gastrointestinal tissues were higher in $\mathrm{Muc1}^{-/-}$mice, regardless of inoculation dose.

Sampling of mice over the first 24 hours of infection revealed rapid transit of $C$. jejuni through the gastrointestinal tract, reaching the large intestine within 2 hours of inoculation in

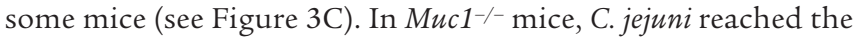
liver of 2 of 4 animals after just 2 hours and 3 of 4 animals by 24 hours, demonstrating that $C$. jejuni penetrates the gastrointestinal barrier rapidly in $\mathrm{Muc1}^{-/-}$mice. Despite the development of systemic infection, $\mathrm{Muc1}^{-/-}$mice did not develop diarrhea or overt signs of illness, with the exception of a reduced gain in body weight 1-3 days after infection compared with uninfected $M u c 1^{-/-}$mice and infected and uninfected $M u c 1^{+/+}$mice (not shown). Systemic infection of $\mathrm{Muc1}^{-/-}$mice by C. jejuni was not restricted to the 81116 strain; other strains equally colonized systemic organs (see Supplemental Figure 2).

Long-term infection experiments demonstrated that C. jejuni eventually crossed the gastrointestinal barrier and colonized systemic organs of $\mathrm{Muc1}^{+/+}$mice (see Figure 3D). Fourteen days following infection, colonization levels in gastrointestinal tissues did not differ significantly between $\mathrm{Muc1}^{-{ }^{--}}$and $\mathrm{Muc1}^{+/+}$mice, and C. jejuni were cultured from systemic organs of all $\mathrm{Muc1}^{+/+}$mice. Four weeks following inoculation, C. jejuni continued to colonize the gastrointestinal tract of all $\mathrm{Muc1}^{-/-}$and $\mathrm{Muc1}^{+/+}$mice, albeit at significantly decreased levels, consistent with partial immunological control (see Figure 3D).
More severe damage to the intestinal epithelium occurs in C. jejuniinfected $\mathrm{Muc1}^{-/-}$mice. Small foci of epithelial damage in the small intestines were observed in $\mathrm{Muc1}^{-/-}$mice within 24 hours of inoculation with C. jejuni (see Figure 4A). In experiments from 1 to 6 days after inoculation, foci of damage were more frequently seen in $\mathrm{Muc1}^{-/-}$mice. Damage took the form of clusters of enucleated and shed epithelial cells on villi, consistent with necrotic cell death following infection or the action of a bacterial toxin (see Figure 4A and Supplemental Figure 3). These areas of damage had the same morphological appearance as the areas where Muc1 expression was upregulated in wild-type mice (see Supplemental Figure 1). Clusters of apoptotic nuclei were occasionally seen within the small intestinal lumen (Figure 4A). Immunohistochemistry demonstrated localized activation of caspase- 3 in damaged small intestinal villous epithelium (Figure 4B). Two hours after infection, multiple foci of villous epithelial cells expressing activated caspase- 3 were seen in 4 of $4 \mathrm{Muc1}^{-/-}$mice and only 1 of 4 wild-type mice, indicating that the infection rapidly triggered foci of epithelial apoptosis, particularly in $\mathrm{Muc1}^{-/-}$mice (Figure 4B).

In both $\mathrm{Muc1}^{-/-}$and $\mathrm{Muc1}^{+/+}$mice, C. jejuni was detected immunohistochemically within gastric epithelial cells and intestinal goblet cell thecae 2 hours after inoculation, consistent with chemotaxis toward mucins or another component of mucus and an ability to invade cells (see Figure 4C). C. jejuni appeared within mucosal luminal secretions, and bacteria could be seen being extruded from infected goblet cells undergoing compound mucin exocytosis (see Figure 4C). C. jejuni was also detected within or adjacent to sites of small intestinal epithelial damage in both $\mathrm{Muc1}^{-/-}$and $\mathrm{Muc1}^{+/+}$mice. Examples of C. jejuni within gastric and small and large intestinal submucosal blood vessels were seen in both $\mathrm{Muc1}^{-/-}$and $\mathrm{Muc1}^{+/+}$ mice within the first 24 hours of infection. In $\mathrm{Muc1}^{-1-}$ mice with 
A

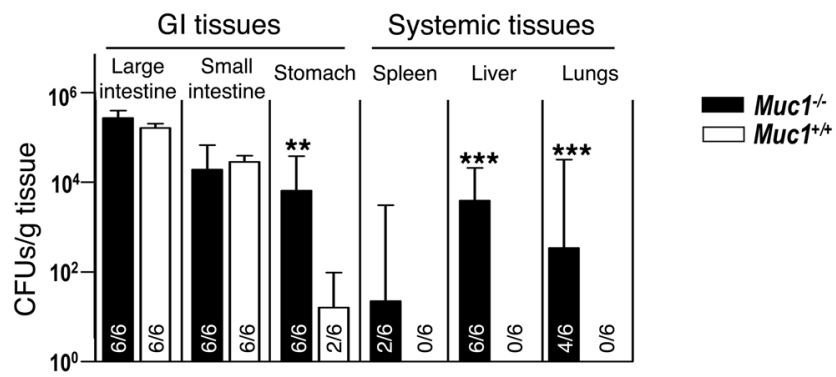

B
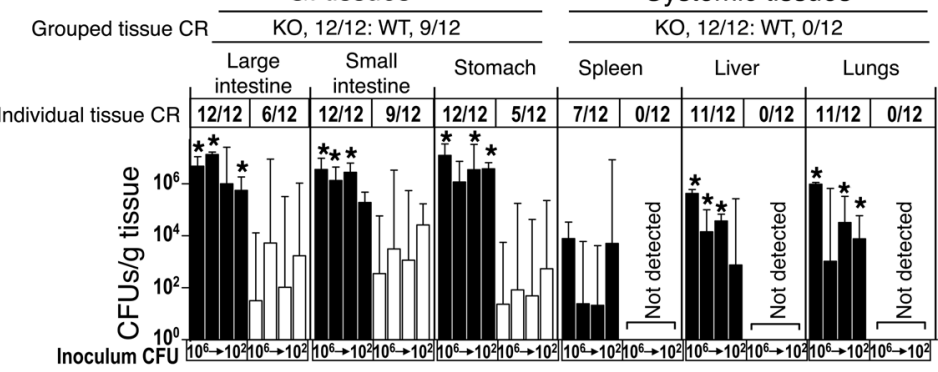

C

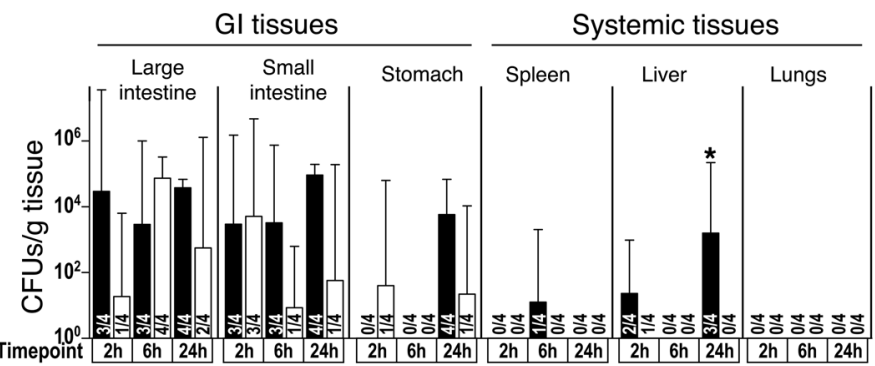

D

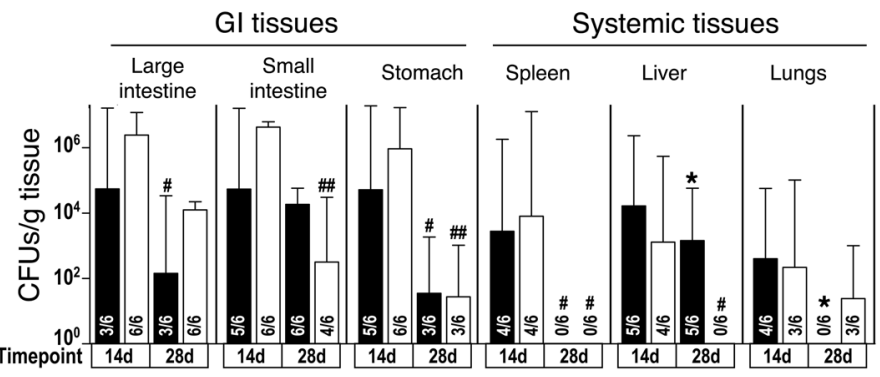

Figure 3

Muc1 $1^{-1-}$ mice are more susceptible to systemic infection by $C$. jejuni. Concentrations of $C$. jejuni in homogenized gastrointestinal and systemic tissues of $\mathrm{MuC1}^{-/-}$and Muc1 $^{+/+} 129 / \mathrm{SvJ}$ mice after oral inoculation with $C$. jejuni strain 81116. Mean \pm SD of CFUs/g tissue. The colonization frequency (number of animals from which colonies were obtained/total number in the group) is shown at the base of each histogram (A, C, and $\mathbf{D})$ or as pooled data for tissues and tissue types (B). (A) Six days after inoculation with $10^{8}$ bacteria. (B) Four days after inoculation with $10^{6}, 10^{4}, 10^{3}$, and $10^{2}$ bacteria. (C) Two, 6 , and 24 hours after inoculation with $10^{4}$ bacteria. (D) Fourteen and 28 days after inoculation with $10^{3}$ bacteria. (A and D) ANOVA, Tukey's post-hoc test; (B and C) Mann-Whitney $U$ test. ${ }^{*} P<0.05$, Muc1 $^{-/-}$versus Muc1+/+; $\# P<0.05,14$ days versus 28 days; ${ }^{* *} P<0.01$, Muc1 $^{-1-}$ versus $M u c 1^{+/+} ; \# P<0.01$, 14 days versus 28 days; ${ }^{* *} P<0.001$. C. jejuni was not detected in uninfected $\mathrm{MuC1}^{-/-}$and $\mathrm{Muc1}^{+/+}$mice (not shown). GI, gastrointestinal.

S. typhimurium in $\mathrm{Muc1}^{1^{-/}}$and $\mathrm{Muc1}^{+/+}$mice as a model for a pathogen known to bypass the mucus barrier. $\mathrm{Muc1}^{-/-}$ and $\mathrm{Muc1}^{+/+}$mice developed systemic infection at similar levels within 2 days of inoculation with $10^{2}$ S. typhimurium strain 8216915 (see Supplemental Figure 4).

Rapid systemic infection with C. jejuni in $\mathrm{Muc1}^{-{ }^{-}}$mice is not due to a bematopoietic deficiency in Muc1. In addition to expression by epithelial cells, MUC1 is expressed by hematopoietic cells including erythroid progenitor cells, monocytes, plasma cells, and activated $\mathrm{T}$ cells and dendritic cells (22-25). The role of MUC1 on hematopoietic cells is unclear although there is evidence that it associates with kinases and may modulate $T$ cell activation $(3,26,27)$. Penetration of the gas-

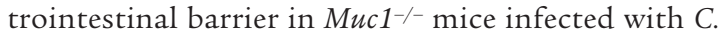
jejuni substantially predates deployment of the effector arms of adaptive immunity. Nevertheless, it could be argued that a deficiency in Muc1 in hematopoietic cells involved in rapidly engaged innate immunity contributes to the epithelial damage and development of systemic infection we describe. Therefore, we repeated infection experiments after systemic depletion of neutrophils and macrophages and generated chimeric

CFU-detected liver infection, C. jejuni was localized within the parenchyma and sinusoids of the liver (Figure 4C). After long-term infection (14 and 28 days), $\mathrm{Muc1}^{+/+}$mice had multiple foci of intestinal epithelial damage at frequencies similar to those observed in the first week of infection in $\mathrm{Muc1}^{-/-}$mice (see Supplemental Figure 3). Small and large intestinal-associated lymphoid tissue increased progressively in both $\mathrm{Muc1}^{-/-}$and $\mathrm{Muc1}^{+/+}$mice, and mild inflammation (lymphoid accumulation with aberrant crypts) was observed in a subset of mice of both strains 2 and 4 weeks after inoculation (see Supplemental Figure 3). Mice of both strains developed cystic lesions in the stomach (see Supplemental Figure 3).

Muc1-deficient mice show no evidence of increased susceptibility to infection with Salmonella typhimurium. Salmonella typhimurium circumvents the mucus barrier to infection by selectively targeting $M$ cells (20). The dome epithelium in which $\mathrm{M}$ cells reside lacks an overlay of mucus and has an altered glycocalyx (21); however, it is not known whether $\mathrm{M}$ cells express Muc1. We compared infection by mice using bone marrow transplantation to evaluate the significance of hematopoietic Muc1 deficiency.

Depletion of phagocytes in $\mathrm{Muc1}^{+/+}$mice only slightly enhanced susceptibility to infection with C. jejuni, with 2 of 5 macrophageand 1 of 6 neutrophil-depleted mice developing systemic infection (see Figure 5, A and B), indicating that phagocytes contribute to limiting initial infection. However, levels of systemic colonization of nondepleted and both macrophage- and neutrophil-depleted $\mathrm{Muc1}^{-/-}$mice were significantly higher than in phagocyte-depleted $\mathrm{Muc1}^{+/+}$mice.

Bone marrow transplantation following lethal irradiation clearly demonstrated that increased susceptibility to early systemic infection in $\mathrm{Muc1}^{-/-}$mice is not due to a Muc1 deficiency in hemato-

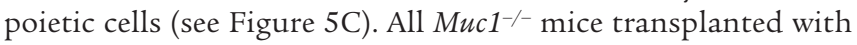
$\mathrm{Muc1}^{-/-}\left(6\right.$ of 6) and $\mathrm{Muc1}^{+/+}$(5 of 5) bone marrow developed systemic infection within 2 days of inoculation with C. jejuni whereas systemic infection was not seen in $\mathrm{Muc1}^{+/+}$mice transplanted with 
either $\mathrm{Muc1}^{+/+}(0$ of 6$)$ or $M u c 1^{-/-}(0$ of 5) bone marrow. Despite a postulated role for Muc1 in T cell activation, the number of circulating $\mathrm{CD}^{+} \mathrm{T}$ cells and the proportion of activated $\mathrm{CD}^{+} \mathrm{CD} 69^{+} \mathrm{T}$ cells did not differ among groups of mice in the transplantation experiment (see Supplemental Figure 5).

Diminution of gastrointestinal flora with antibiotics increases susceptibility of $\mathrm{Muc1}^{+/+}$mice to systemic infection with C. jejuni. Previous studies show increased gastrointestinal levels of C. jejuni after infection of germ-free (28) and antibiotic-treated mice (29). Pretreatment of $\mathrm{Muc1}^{-/-}$and $\mathrm{Muc1}^{+/+}$mice with broad-spectrum antibiotics to reduce normal microflora significantly increased the levels of gastrointestinal tract colonization, caused several histological foci of intestinal damage, and induced early (within 2 days) systemic infection in all $\mathrm{Mucl}^{+/+}$mice, abolishing the differences in susceptibility between $\mathrm{Muc1}^{-/-}$and $\mathrm{Muc1}^{+/+}$mice (see Figure 6A). This introduced the possibility that the enhanced susceptibility to infection of $\mathrm{Muc1}^{-/-}$mice was due to an alteration in their intestinal bacterial flora. However, quantitative assessment of the intestinal bacterial flora of $\mathrm{Muc1}^{-/-}$and $\mathrm{Muc1}^{+/+}$mice demonstrated equivalent numbers of bacteria and a virtually identical relative abundance of the major phyla and subphyla (see Figure 6B).

Expression of MUC1 in intestinal cells increases resistance to $C$. jejuni CDT in vitro. The type of intestinal damage we observed in mice infected with C. jejuni was consistent with the action of a toxin. C. jejuni produces a genotoxin (CDT) with nuclease activity that triggers cell-cycle arrest and increased apoptosis in vitro (30). MUC1 has been shown to modulate apoptosis and cell-cycle progression in malignant epithelial cells in response to genotoxic stress, in part by interacting with the regulatory domain of the p53 transcription factor (14-16). HeLa cervical cancer cells express MUC1 and have been shown to be susceptible to CDT (31). Treatment of HeLa cells with strain 81116-derived CDT resulted in almost complete redistribution of the MUC1 extracellular domain from the cell surface to the nucleus within 24 hours (see Figure 7A). CDT induced both cell-cycle arrest and apoptosis in HeLa cells in a dose-dependent manner. Stable partial knockdown of MUC1 with short-hairpin RNA (shRNA) did not enhance CDT-induced cell-cycle arrest or apoptosis over that seen with a control shRNA (representative experiment at 48 hours shown in Figure 7B, similar results were obtained at 72 and 96 hours). Because HeLa cells have very low functional p53 due to the presence of the HPV E6 protein (32), we transfected MUC1 in the p53-expressing HCT116 intestinal cell line in which transfection of MUC1 had previously been shown to increase resistance to chemotherapeutic genotoxins (16). In this cell line, CDT caused the MUC1 extracellular domain to accumulate in cytoplasmic vesicles, but it was not seen within the nucleus (see Figure 7C). In HCT116 cells, CDT caused dosedependent cellular distension and cell-cycle arrest but did not induce apoptosis at doses resulting in complete arrest. HCT116 cells expressing MUC1 proliferated more in the presence of CDT, showing that MUC1 protects intestinal cells from the activity of C. jejuni CDT (results from 2 independent experiments are shown in Figure 7D). The MUC1 cytoplasmic domain translocated to the nucleus in a small proportion of CDT-affected cells within 24 hours of exposure to CDT with very strong nuclear staining. This pattern is consistent with transient relocation to the nucleus or relocation only in the most severely affected cells, and a role for MUC1 in modulation of transcription (Figure 7E). p53 showed diffuse colocalization with the MUC1 cytoplasmic domain in the cytoplasm of untreated cells and strong colocalization in cytoplas- mic vesicles in CDT-treated cells (see Figure 7E). p53 translocated to the nucleus in the vast majority of CDT-treated MUC1-expressing HCT116 cells. Taken together, these data support a p53-mediated mechanism of MUC1 resistance to CDT.

CDT-null C. jejuni show lower gastric colonization but equivalent penetration of the intestinal barrier in $\mathrm{Muc1}^{-/-}$mice in vivo. Chloramphenicol-resistant C. jejuni strain 81-176 with the CDT-B gene deleted $(\triangle \mathrm{CDT}-\mathrm{B})$ has been shown to cause less inflammation in a 4 - and 8 -week chronic infection model in NF- $\mathrm{KB}$ p50-/- $\mathrm{p} 65^{+/-}$mice (33). Wild-type 81-176 and an isogenic $\triangle \mathrm{CDT}-\mathrm{B}$ mutant were inoculated into $\mathrm{Muc1}^{-/-}$and $\mathrm{Muc1}^{+/+}$mice and colonization of gastrointestinal and systemic tissues analyzed after 48 hours (Figure 8A).

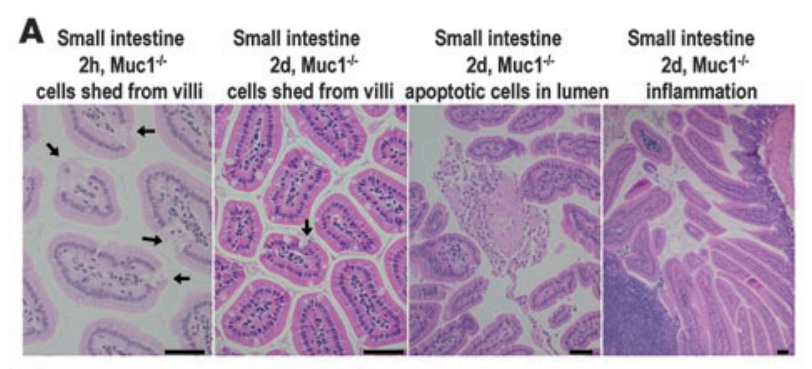

B Small intestine, $6 \mathrm{~h}$, Muc1 $^{+}$ Activated caspase- 3 in damaged cells

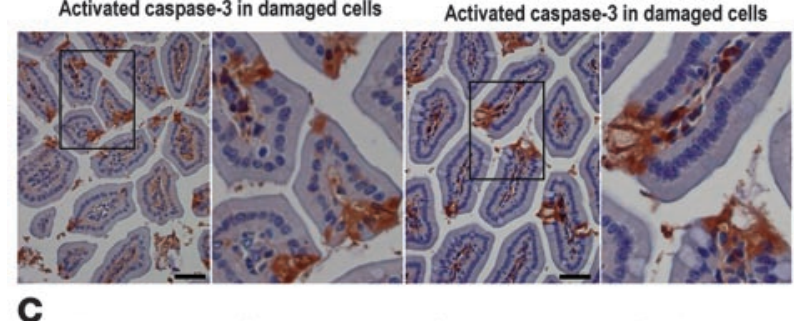

C

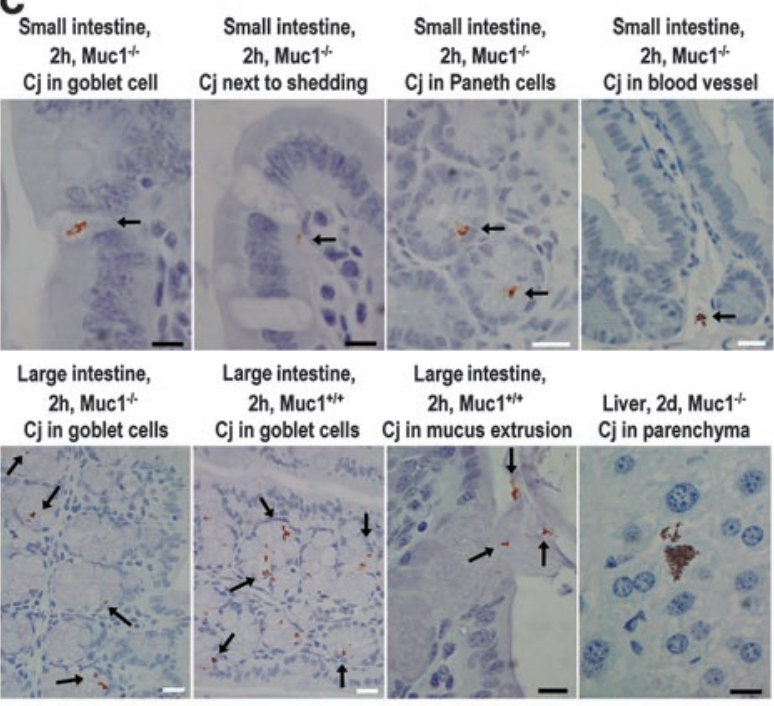

Figure 4

Epithelial damage and apoptosis and localization of bacteria in the gastrointestinal epithelium of C. jejuni-infected $\mathrm{MuC1}^{-/-}$and $\mathrm{MuC1}^{+/+}$ mice. Tissue type, mouse genotype, time after inoculation, and a summary of the features demonstrated are shown above each photomicrograph. (A) H\&E staining; arrows show shed epithelial cells. Immunohistochemical detection counterstained with hematoxylin of (B) activated caspase-3 and (C) C. jejuni (Cj). Arrows indicate the presence of $C$. jejuni. Scale bars: $50 \mu \mathrm{m}(\mathbf{A}$ and $\mathbf{B})$; white scale bars: $20 \mu \mathrm{m}(\mathbf{C})$; black scale bars: $10 \mu \mathrm{m}(\mathbf{C})$. 
A

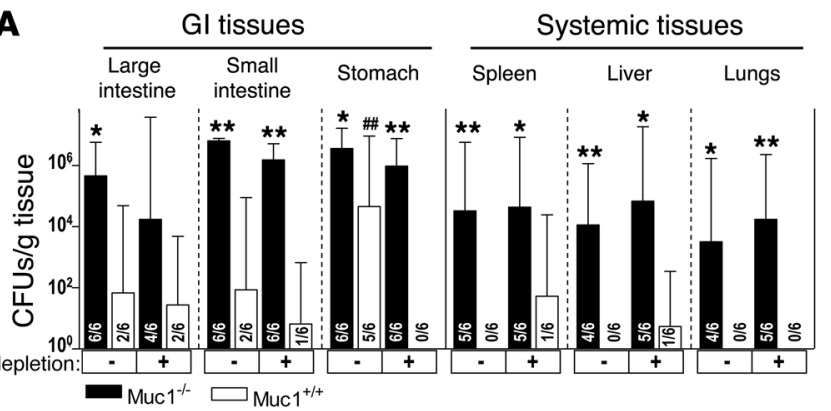

B

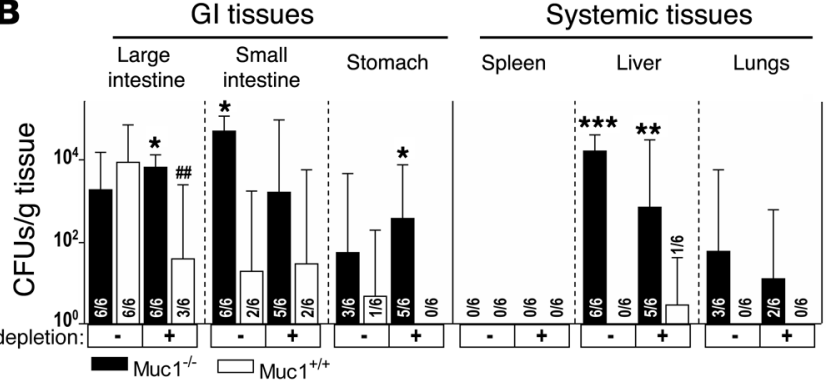

C

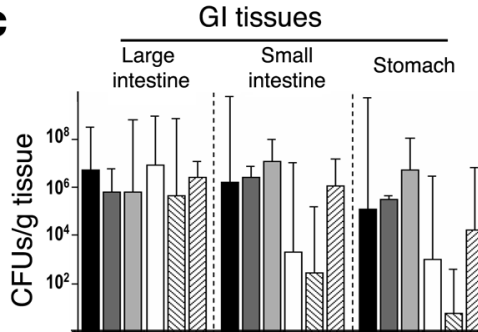

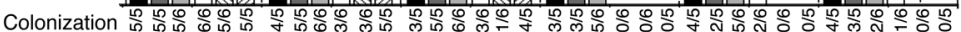

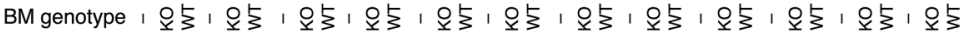

\section{Figure 5}

Rapid systemic infection with $\mathrm{C}$. jejuni in $\mathrm{Muc1}^{-1-}$ mice is not due to a hematopoietic deficiency in Muc1. Concentrations of $C$. jejuni in gastrointestinal and systemic tissues of macrophage-depleted (A), neutrophil-depleted

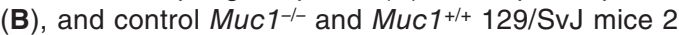
days after oral inoculation with $10^{4} \mathrm{C}$. jejuni strain 81116. Neutrophil depletion was confirmed by flow cytometry on peripheral blood (not shown). Mean \pm SD of CFUs $/ g$ tissue. Colonization frequency is shown at the base of each histogram. ANOVA, Tukey's post-hoc test; ${ }^{\star} P<0.05, \mathrm{Muc1}^{-/-}$versus Muc1 ${ }^{+/+} ;{ }^{*} P<0.01$, Muc1 ${ }^{-/-}$ versus $\mathrm{MuC1}^{+/+} ; \# P<0.01$, phagocyte-depleted versus control; ${ }^{* \star *} P<0.001$, Muc1 $^{-/-}$versus Muc1 ${ }^{+/+}$. M $\phi$, macrophage; Neut, neutrophil. (C) Concentrations of C. jejuni in gastrointestinal and systemic tissues from $\mathrm{KO}$ and $\mathrm{MuC1+/+}$ (WT) mice infected 6 months after lethal irradiation and transplantation of bone marrow from Muc1-/- $(\mathrm{KO})$ and $\mathrm{MuC1}^{+/+}$(WT) mice and in nontransplanted (-) control mice of the same age. Mean \pm SD CFUs/g tissue 2 days after oral inoculation with $10^{4}$ C. jejuni. Colonization frequency is shown at the base of each histogram. ANOVA, Tukey's post-hoc test; ${ }^{*} P<0.05$, Muc $^{-/-}$versus Muc1 ${ }^{+/+}$.

Mouse genotype $\overline{\mathrm{KO}} \overline{\mathrm{WT}} \overline{\mathrm{KO}} \frac{\overline{\mathrm{WT}}}{\mathrm{KO}} \overline{\mathrm{WT}} \frac{\mathrm{KO}}{\mathrm{WT}} \frac{\mathrm{KO}}{\mathrm{WT}} \frac{\mathrm{KO}}{\mathrm{KT}}$

Wild-type 81-176 showed greater colonization of the gastrointestinal and systemic tissues of $M u c 1^{-/-}$compared with $M u c 1^{+/+}$mice, verifying the susceptibility of $M u c 1^{-/-}$mice to C. jejuni infection. In $\mathrm{Muc1}^{-{ }^{--}}$mice, significantly lower levels of colonization by the $\Delta$ CDT-B mutant occurred in the stomach but not in the intestine. This finding suggests that in the stomach, where Muc1 expression is highest, MUC1-mediated resistance to the action of CDT is a component of the consistently lower levels of C. jejuni colonization in wild-type mice. However, the $\triangle \mathrm{CDT}-\mathrm{B}$ mutant crossed the gastrointestinal barrier in $\mathrm{Mucl}^{-/-}$mice, indicating that the action of CDT is not the primary determinant of systemic infection in mice lacking Muc1. Quantitative assessment of concentrations of apoptosis-associated activated caspases 3 and 7 in a segment of the terminal ileum of mice infected in the experiment shown in Figure 8A revealed increased apoptosis in infected mice, with trends toward greater apoptosis in $\mathrm{Muc1}^{-/-}$than $\mathrm{Muc1}^{+/+}$mice infected with wildtype C. jejuni, and lower apoptosis in mice infected with the $\triangle \mathrm{CDT}-\mathrm{B}$ mutant (Figure 8B). The variation among animals in these samples is consistent with the focal nature of activated caspase- 3 staining observed by immunohistochemistry.

\section{Discussion}

This study provides what we believe is the first empirical in vivo evidence that mucins are a critical element of gastrointestinal mucosal defense against pathogens. Alterations in expression of
Muc1 in the gastrointestinal tract following bacterial infection, together with evidence that C. jejuni more heavily colonizes the gastrointestinal tract, induces more epithelial damage, and readily crosses the gastrointestinal barrier in $\mathrm{Muc1}^{-/-}$mice, demonstrate that this mucin is part of a dynamic epithelial response to the presence of bacterial pathogens. Bone marrow transplantation provided conclusive evidence that Muc1 expression by epithelia, and not the contribution to innate or adaptive immunity of Muc1 expressed by cells of hematopoietic lineage, protected mice from systemic infection by C. jejuni. Furthermore, phagocyte depletion experiments demonstrated Muc1 was a more significant element of protection from systemic C. jejuni infection than phagocytes. By manipulating MUC1 expression in epithelial cells in vitro we showed that MUC1 protects cells from a C. jejuni genotoxin. We propose that this mucin, rather than being part of a static barrier, is part of a dynamic response to mucosal infection that interacts with and is regulated by elements of both innate and adaptive immunity. We propose that the cell surface mucins have evolved as a critical defense against potential pathogens that penetrate the physical and chemical barrier provided by secreted mucus.

Our data provide clear experimental evidence confirming previous uncontrolled observational studies that suggested $\mathrm{Muc1}^{-/-}$ mice housed under conventional conditions were more susceptible to reproductive tract and ocular infection by environmental bacteria $(11,12)$. Our observations of increased susceptibility to 
infection by mucin-binding bacteria in $\mathrm{Muc1}^{-/-}$mice are consistent with molecular epidemiological studies linking polymorphisms in the length of the MUC1 extracellular domain with development of gastritis and gastric cancer following infection with the mucinbinding gastric pathogen $H$. pylori (34-37). While $M u c 1^{-/-}$mice showed dramatically increased susceptibility to systemic infection by C. jejuni, no differences were demonstrated with an intestinal pathogen, S. typhimurium, that targets M cells, thereby circumventing the cell surface mucin barrier.

Based on our data and the biochemical properties of cell surface mucins, we propose that cell surface mucins act at 2 levels in host defence against infection. Initially, the large extracellular domain (for Muc1 estimated to be 200-500 nm in length; ref. 38) expressing diverse and complex oligosaccharides acts as a releasable decoy ligand for bacterial adhesins, thereby limiting attachment of pathogens to other cell surface molecules and subsequent invasion. Cell surface mucins are cleaved at a SEA module during synthesis, facilitating subsequent release of the extracellular domain (39). The MUC1 extracellular domain can also be released by proteolytic cleavage by the enzymes TACE (ADAM17) (40) and MT1-MMP (41). Proteases may cleave the mucin following bacterial adherence or highly motile C. jejuni could disrupt the noncovalent interaction at the SEA module. Secondly, we propose that following release of the extracellular domain, cytoplasmic domain signaling and translocation of the cytoplasmic subunit to mitochondria and, in combination with p53, to the nucleus, modulate appropriate activation, growth, and apoptosis of mucosal epithelial cells encountering bacterial pathogens and their toxins.

There is now considerable evidence that C. jejuni is chemoattracted to mucin and capable of adhering to specific mucin carbohydrates, supporting our contention that mucins can act as decoy ligands. The evidence includes our in vitro demonstration of binding to murine mucins and the $\mathrm{H}$ type 2 structure in particular as well as the rapid localization of C. jejuni within goblet cell thecae following infection and more rapid binding to MUC1-expressing intestinal cells in vitro together with previous studies showing chemotaxis toward porcine gastric mucin in vitro (17) and binding to human milk mucin-type oligosaccharides (18). Coadministration of human milk reduces $C$. jejuni colonization of the murine gastrointestinal tract (18). Interestingly, Muc1 is a major component of milk and so may mediate this effect. Although Muc1 is expressed on the apical membrane surface, it is also present between granules of stored secretory mucins in intestinal goblet cells (42). This reservoir of MUC1 is released during exocytosis and thereby becomes a constituent of mucus. In our study, Muc1 was present in the lumen of the stomach and large intestine following C. jejuni infection, consistent with increased shedding from the cell surface or direct secretion from epithelial cells, further supporting a role as a decoy ligand. Although MUC1 did not inhibit invasion of epithelial monolayers in vitro, these cocultures do not reproduce the in vivo environment. In particular, due to the absence of goblet cells, the cultures lack the secreted mucus layer within which shed MUC1 can accumulate in vivo.

The C. jejuni CDT has nuclease activity and triggers cell-cycle arrest in vitro (30). C. jejuni mutants lacking CDT show equal gastrointestinal tract colonization but impaired invasiveness into blood, spleen, and liver in SCID mice (31) and diminished chronic enteritis in NF-кB-deficient mice (33), demonstrating the importance of this toxin in vivo, at least in immunocompromised animals. Our demonstration of greater resistance to

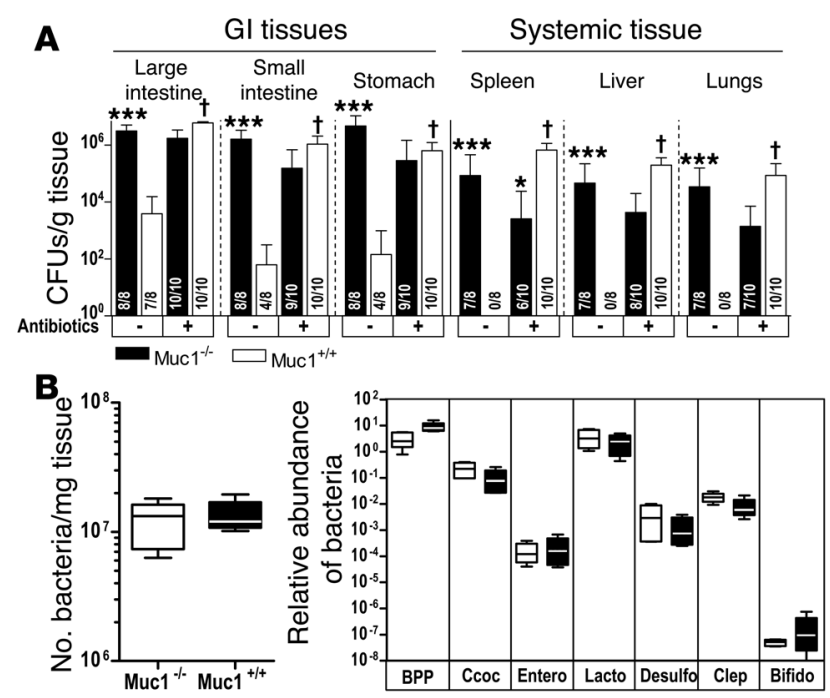

\section{Figure 6}

Reduced bacterial flora increases susceptibility of $M u c 1^{+/+}$mice to $C$. jejuni infection, but bacterial flora is not altered in $M u c 1^{-/-}$mice. (A) Concentrations of $C$. jejuni in gastrointestinal and systemic tissues of $\mathrm{MuC1}^{-1-}$ and $\mathrm{MuC1}^{+/+} 129 / \mathrm{SvJ}$ mice after oral inoculation with $10^{5} \mathrm{C}$. jejuni strain 81116 with (+) and without (-) treatment with broad spectrum oral antibiotics for 7 days. Antibiotics were withdrawn 24 hours prior to inoculation. Mean \pm SD of CFUs/g tissue. Colonization frequency is shown at the base of each histogram. ANOVA, Tukey's post-hoc test; ${ }^{*} P<0.05$, Muc1-/versus $\mathrm{Muc1}^{+/+}$; ${ }^{* \star} P<0.001, \mathrm{Muc1}^{-/-}$versus $\mathrm{Muc1^{+/+ }}{ }^{\dagger} P<0.001$, antibiotics versus control. (B) Number of bacteria in the entire large intestine was estimated by counting SYBR green-stained bacteria on filtered fixed tissue homogenates. DNA was extracted from feces of $\mathrm{MuC1}^{-/-}$and $\mathrm{MuC1}^{+/+}$mice and quantitative PCR used to amplify 16S ribosomal DNA and quantify the abundance of major intestinal bacterial groups. BPP, Bacteroides-Prevotella-Porphyromonas group; Ccoc, C. coccoides group; Entero, Enterococcus spp; Lacto, Lactobacillus group; Desulfo, Desulfovibrio group; Clep, C. leptum subgroup; Bifido, Bifidobacterium genus. Results in individual mice were expressed as a proportion of the result for universal bacterial $16 \mathrm{~S}$ ribosomal DNA primers. Box plots show medians, quartiles, and ranges.

CDT by MUC1-expressing human intestinal cells in vitro and the absence of increased gastric colonization in $\mathrm{Muc1}^{-/-}$mice by $\mathrm{C}$. jejuni lacking CDT is consistent with a role for MUC1 in suppressing the activity of genotoxins in the gastrointestinal tract. MUC1 is phosphorylated in response to binding bacteria (4), interacts with growth factor receptors involved in epithelial repair (13), and inhibits the intrinsic pathway of apoptosis in malignant epithelial cells in response to genotoxic stress by (a) localizing to mitochondria, stimulating the phosphorylation of Akt and Bad, and upregulating mitochondrial $\mathrm{Bcl}-\mathrm{X}_{\mathrm{L}}(14,16)$ and $(\mathrm{b})$ binding to the regulatory domain of p53 and moving in a complex to the nucleus, attenuating activation of Bax transcription (15). MUC1 binding to $\mathrm{p} 53$ also promotes transcription of p21, facilitating cell-cycle arrest at the $\mathrm{G} 1$ checkpoint (15). The rapid upregulation and enhanced cytoplasmic localization of the Muc1 cytoplasmic domain in gastrointestinal epithelial cells exposed to C. jejuni in vivo are therefore consistent with an intracellular role for this mucin. We demonstrate that, in vitro, the MUC1 extracellular domain is internalized and the cytoplasmic domain translocates to the nucleus in CDT-affected cells. Wei et al. estimated that, 
A

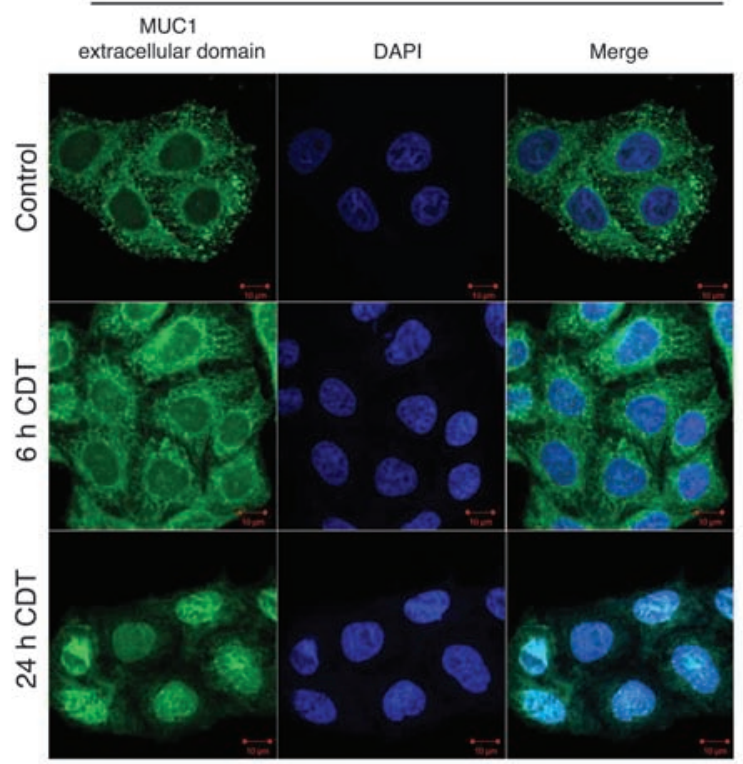

B

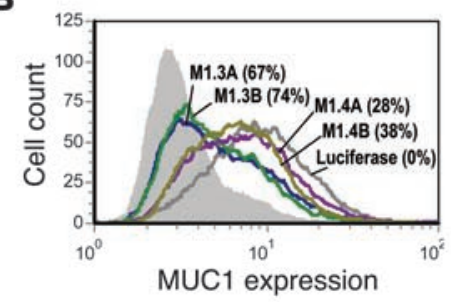

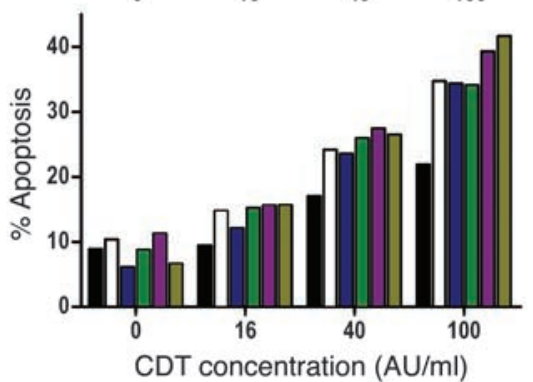

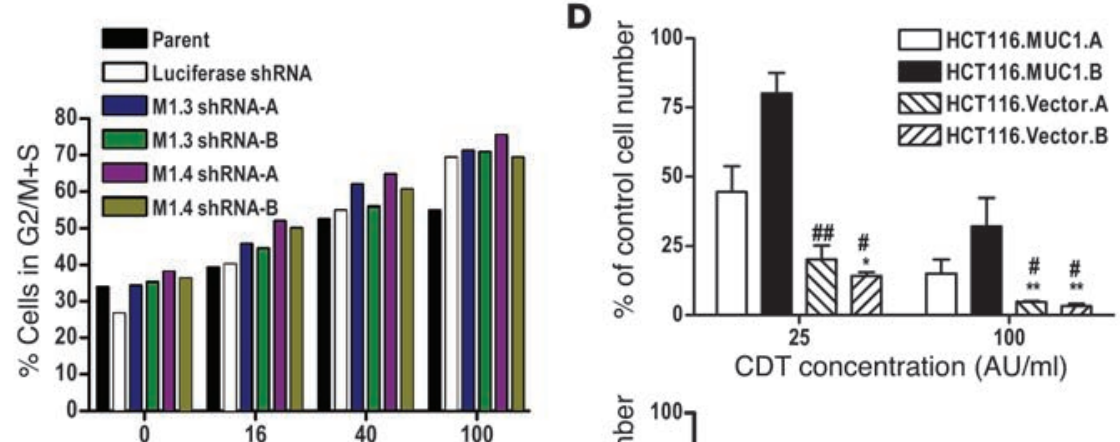

C

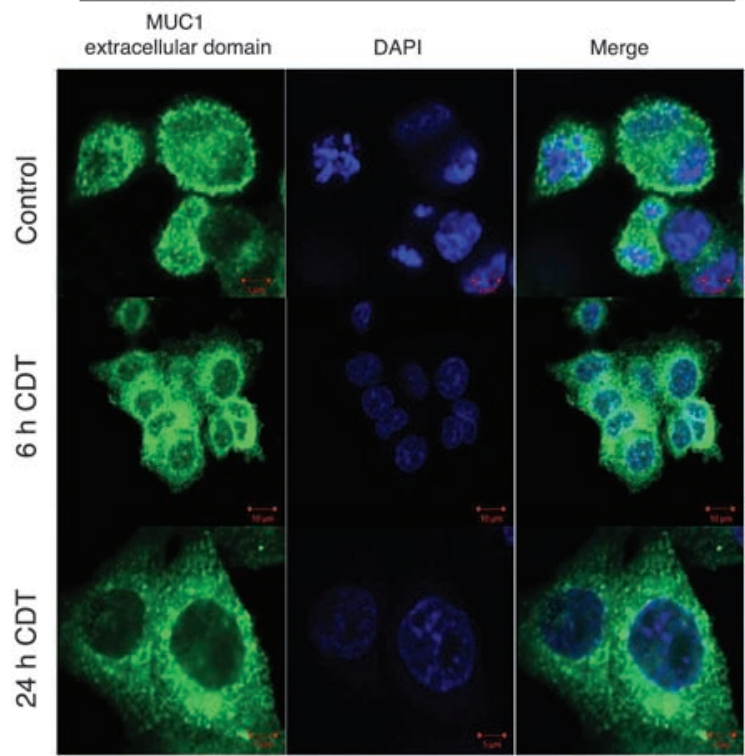

D

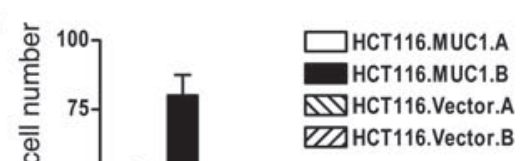

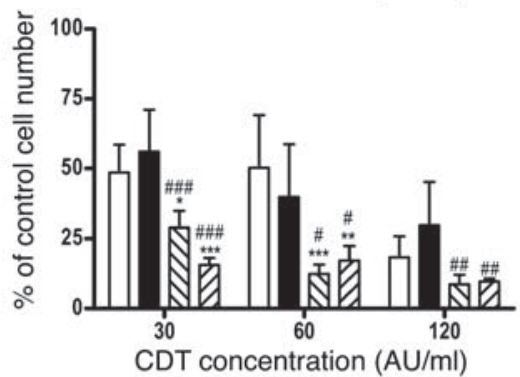

$\mathbf{E}$

HCT116 EM10

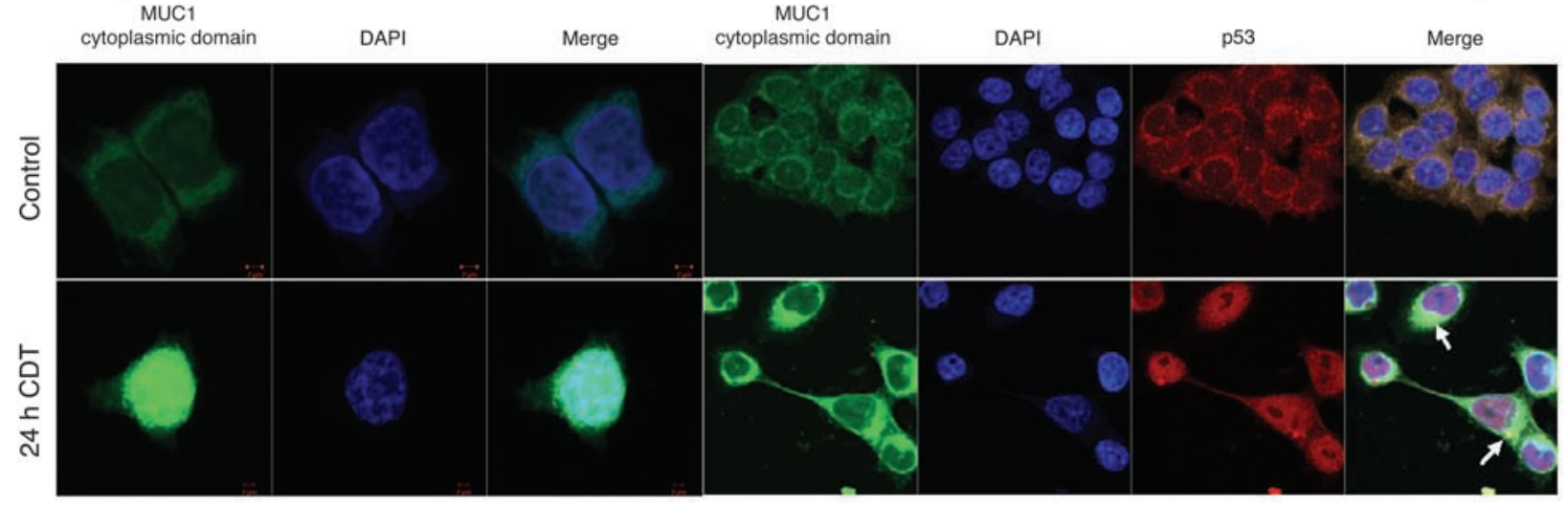




\section{Figure 7}

MUC1 protects epithelial cells from the C. jejuni CDT. (A) HeLa cells were exposed to $200 \mathrm{AU} / \mathrm{ml}$ CDT for 0, 6, or 24 hours. MUC1 extracellular domain and nuclei were stained and examined by confocal microscopy. (B) MUC1 expression in HeLa cervical cancer cells stably expressing 2 differing MUC1 shRNAs (M1.3, M1.4, 2 cultures, A and B, for each shRNA) or a control (luciferase) shRNA were determined by flow cytometry (shaded area represents control antibody; lines show MUC1 staining); percentage decrease in median fluorescence in parentheses. Parent cells and the sublines were exposed to 16-100 AU/ml of CDT for 48 hours. The proportion of cells in the S/G2+M phases of the cell cycle and the percentage of cells in apoptosis (annexin V-positive) were determined by flow cytometry. (C) The EM10 MUC1-expressing clone of HCT116 cells was exposed to $200 \mathrm{AU} / \mathrm{ml}$ CDT for 0,6 , or 24 hours and stained as in A. (D) Stable clones of HCT116 cells transfected with MUC1 or the pcDNA3 vector (see MUC1 expression in Figure 2D) were exposed to CDT for 96 hours, and cells were counted and expressed as a proportion of control vehicle-only treated cultures. Two distinct experiments are shown. ANOVA, Tukey's post-hoc test; ${ }^{*} P<0.05$ versus HCT116.MUC1.A; ${ }^{\#} P<0.05$ versus HCT116.MUC1.B; ${ }^{* \star} P<0.01$ versus HCT116.MUC1.A; \#\# $P<0.01$ versus HCT116.MUC1.B; ${ }^{* \star *} P<0.001$ versus HCT116. MUC1.A; \#\#\# < 0.001 versus HCT116.MUC1.B. (E) The EM10 MUC1-expressing clone of HCT116 cells was exposed to 200 AU/ml CDT for 0 or 24 hours. MUC1 cytoplasmic domain, p53, and nuclei were stained and examined by confocal microscopy; arrows highlight colocalization of MUC1 and p53 in cytoplasmic vesicles.

in MUC1-transfected HCT116 cells, about 4\% of the cytosolic pool of the MUC1 cytoplasmic domain is bound to p53 (15). We show colocalization of the MUC1 cytoplasmic domain and p53 and translocation of both proteins to the nucleus in CDT-treated intestinal cells. The lack of a protective effect of MUC1 in HeLa cells is likely to be due to their lack of functional p53 to partner MUC1 (31), with the lack of 553 perhaps also explaining the high level of apoptosis induced by CDT in this cell line. Translocation of the MUC1 extracellular domain to the nucleus in CDT-treated HeLa cells was unexpected and introduces a possible role for p53 in MUC1 stabilization and recycling during stress. Although the ability of MUC1 to protect from genotoxic agents was first reported in the context of cancer, our data demonstrate that this mechanism may have evolved in epithelial cells as a component of mucosal defence against xenobiotic genotoxins. However, the development of systemic infection in $\mathrm{Muc1}^{-/-}$mice infected with C. jejuni lacking CDT demonstrates that although CDT contributes to epithelial damage, it is not the determinant of systemic infection in mice lacking Muc1.

We could find no evidence for an alteration in the number of intestinal bacteria or the relative abundance of major elements of the bacterial flora in $\mathrm{Muc1}^{-/-}$mice, suggesting that cell surface mucins have little effect on the frequency and the diversity of the commensal bacteria that reside on the luminal side of the mucus barrier. In terms of the concept that Muc1 provides a releasable decoy, the cell surface mucins reside under the mucus barrier and are not likely to interact with the vast majority of commensal bacteria. In contrast, gastrointestinal pathogens have evolved mechanisms to cross the mucus barrier and thus will come in contact with the cell surface mucins. Increased systemic infection by $C$. jejuni in antibiotic-treated wild-type mice is likely to be due to an expanded niche for C. jejuni in the absence of commensal flora, as the higher intestinal colonization rates suggest. Although $\mathrm{Muc1}^{-{ }^{--}}$ mice had significantly higher intestinal colonization than $\mathrm{Muc1}^{+/+}$ mice in some experiments, at early time points, systemic infection occurred in $\mathrm{Muc1}^{-/-}$mice while intestinal colonization was several logs less than the level of intestinal colonization reached at later time points in wild-type mice in the absence of systemic infection (see Figure 3C). Taken together, our data suggest that Muc1 does not prevent systemic infection simply by lowering the colonization density of bacteria but that there is a colonization level (such as that achieved after treatment with antibiotics) at which penetration of the gastrointestinal barrier occurs even in the presence of Muc1. Penetration of the gastrointestinal barrier by C. jejuni after 2 weeks in wild-type mice could occur due to progressive epithelial damage, bacterial selection/adaptation to the intestinal microenvironment, and/or altered microenvironment due to host adaptive immune responses.

Elucidation of pathogenicity mechanisms used by C. jejuni has been hampered by lack of clinically relevant animal models of infection. We now provide evidence that C. jejuni binds intestinal mucins, targets goblet cell thecae in vivo, and shows enhanced pathogenicity in the absence of just 1 cell surface mucin. We show that MUC1 protects cells from the actions of a bacterial genotoxin, suggesting that cell surface mucins are not simple blocking molecules on the cell surface but rather have evolved wider roles in protecting epithelial cells from xenobiotic toxins. Polymorphisms in cell surface mucin genes themselves, genes encoding and regulating the glycosyltransferases that assemble their complex carbohydrates, and genes that regulate appropriate mucin production and secretion could all conceivably predispose individuals to both acute infection and chronic inflammatory disease. The results of this study should underpin further exploration of the normal function of members of the cell surface mucin family and their contribution to epithelial diseases.

\section{Methods}

Animals. Muc1 $1^{-/-}$mice on a 129/SvJ background (43) were maintained as

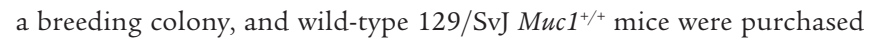
from the Walter and Eliza Hall Institute (Melbourne, Victoria, Australia). Mice were sex and age matched within experiments (6-12 weeks of age unless otherwise specified), housed under clean conventional conditions, and allowed free access to sterilized food and water. All experiments were approved by the University of Queensland Animal Experimentation Ethics Committee (approval nos. 734/05, 586/04, 389/03, and 200/02). Colonies routinely tested negative for murine viral and bacterial pathogens.

Bacterial culture and preparation of CDT. C. jejuni strains 81116, 331, and 81-126 were grown on solid selective agar ( $2 \%$ Columbia agar, $1 \%$ bacteriological agar, $5 \%$ defibrinated horse blood, Skirrow Selective Supplement; Oxoid) under microaerophilic conditions $\left(5 \% \mathrm{O}_{2}, 15 \% \mathrm{CO}_{2}, 80 \% \mathrm{~N}_{2}\right.$; BOC Gases) at $42^{\circ} \mathrm{C}$ for 48 hours. CDT was prepared from cultured C. jejuni 81116 as described (31) with $1 \mathrm{AU}$ corresponding to the toxin prepared from $3.7 \times 10^{5}$ bacteria. Strain 81-126 and $\triangle C D T-B(33)$ were a kind gift from James G. Fox (Massachusetts Institute of Technology, Cambridge, Massachusetts, USA). S. typhimurium strain 8216915 was grown on either solid xylose lysine deoxycholate (XLD) or MacConkey agar (Oxoid) and incubated at $37^{\circ} \mathrm{C}$ overnight under aerobic conditions.

C. jejuni mucin-binding studies. Intestinal secreted mucin (Muc2) was purified from murine intestinal mucus secretions by repetitive extraction of the insoluble mucin in $6 \mathrm{M}$ guanidinium hydrochloride (Sigma-Aldrich) 


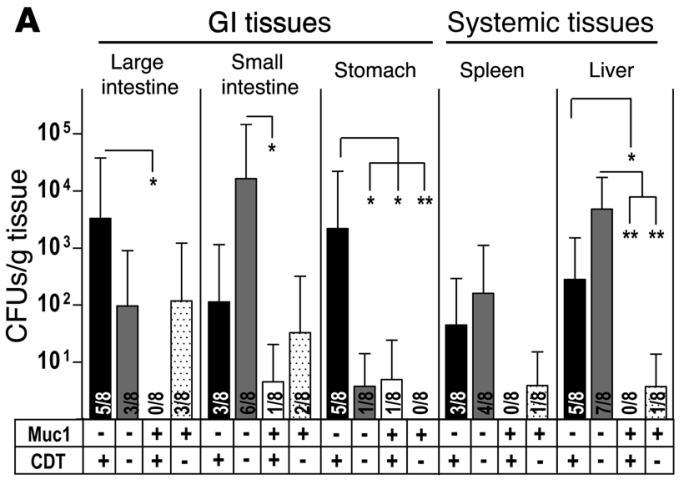

B

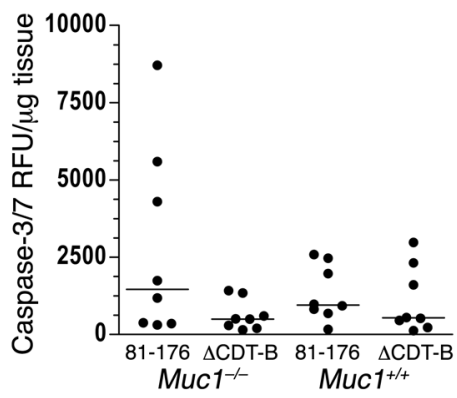

Figure 8

$\triangle$ CDT-B C. jejuni show lower gastric colonization and lower intestinal apoptosis but equivalent penetration of the intestinal barrier in $M u C 1^{-1-}$ mice in vivo. (A) Concentrations of $C$. jejuni in gastrointestinal and systemic tissues of $\mathrm{Muc1}^{-1_{-}}(-)$and $\mathrm{Muc1}^{+/+}(+)$129/SvJ mice 48 hours after oral inoculation with $10^{5} \mathrm{C}$. jejuni strain 81-176 (CDT +) and $\triangle$ CDT-B (CDT -). Mean \pm SEM of CFUs/g tissue. Colonization frequency is shown at the base of each histogram. ANOVA, Tukey's post-hoc test; ${ }^{*} P<0.05$; ${ }^{\star *} P<0.01$. (B) Concentrations of activated apoptosis-associated caspases 3 and 7 determined by the CaspaseGlo 3/7 luminescence assay in 2 pooled 5-mm segments of the terminal ileum of mice in the experiment described in A. A linear scale is used because individual samples showed dilution linearity. RFU, relative fluorescence units.

(44). Purified Muc2 was coated onto 96-well plates (with and without treatment with $0.04 \mathrm{U} / \mathrm{ml}$ neuraminidase), wells were then blocked with BSA, and wells without mucin but blocked with BSA were used to determine nonspecific binding. Biotinylated C. jejuni strain $81116\left(10^{7}\right)$ was resuspended in $0.05 \%$ Tween 20 and $0.5 \%$ human albumin in PBS at $\mathrm{pH}$ 5.0-7.2. Binding of biotinylated C. jejuni was assessed by ELISA using streptavidin-HRP, ABTS (Zymed; Invitrogen) as chromagen, and determination of $A_{405} \mathrm{~nm}$. Le ${ }^{\mathrm{b}}$, sialyl-Le ${ }^{\mathrm{x}}$, and $\mathrm{H}$ type 2 conjugated to human serum albumin (IsoSep AB) were labeled with fluorescein isothiocyanate, and $500 \mathrm{ng}$ was incubated with C. jejuni in PBS containing 0.05\% Tween 20 and $0.5 \%$ human albumin. After washing the bacteria twice by centrifugation, fluorescence was measured using a FLUOstar Optima fluorescence plate reader (BMG LABTECH).

Infection of mice. Bacteria harvested from plate cultures were suspended in warmed Brucella broth or Lauria-Bertani broth (C. jejuni and S. typhimurium, respectively) and the number of organisms determined by $\mathrm{A}_{410} \mathrm{~nm}$ using a standard curve. In a series of experiments, mice were orally inoculated with $10^{2}-10^{8}$ CFUs C. jejuni or $10^{2}-10^{3}$ CFUs S. typhimurium and sacrificed at multiple time points by cervical dislocation. Gastrointestinal tract organs (large intestine, small intestine, and stomach) and systemic organs (spleen, liver, and lungs) were dissected and alternate samples collected in either broth or $10 \%$ formalin. To assess the number of CFUs/g tissue, samples in broth were homogenized, serially diluted, plated onto selective agar, and grown as above.

Phagocyte depletion. Mice were depleted of macrophages by i.p. injection of $1 \mathrm{mg}$ Carrageenan- $\lambda$ (IV) (Sigma-Aldrich) in $200 \mu \mathrm{l}$ PBS, pH 7.2, 48 hours prior to oral inoculation with bacteria. Mice were depleted of neutrophils by i.p. injection of $150 \mu \mathrm{g}$ RB68C5 antibody in $200 \mu \mathrm{l}$ PBS daily for 3 days prior to and including the day of challenge with bacteria. Control mice were injected with the same volume of PBS.

Bone marrow transplantation. Mice (6-8 weeks) were irradiated with 2 doses of 500 cGy delivered 3 hours apart in a Gammacell irradiator (Nordion) (demonstrated in preliminary experiments to be lethal in this strain of mice in the absence of bone marrow transplantation and to result in complete chimerism following transplantation). Following a 60-minute recovery period, $5 \times 10^{6}$ bone marrow cells isolated from the femur and tibia of donor mice were injected i.v. in $200 \mu \mathrm{l}$ sterile L15 medium. Mice were kept for 6 months to ensure full engraftment and maturation of the immune system before experimental challenge with C. jejuni.

Histological assessment and immunohistochemistry. Gastrointestinal tract specimens were fixed in $10 \%$ buffered formalin and embedded in paraffin. For analysis of histological damage, tissue sections stained with $\mathrm{H} \& \mathrm{E}$ were coded to blind the analysis, and the entire section was systematically examined and areas of damage recorded. Muc1 was detected in tissue sections with the CT2 cytoplasmic domain antibody (13) following antigen retrieval in citric acid using a standard biotin-streptavidin detection system and 3,3'-diaminobenzidine tetrahydrochloride as chromagen, then counterstaining with hematoxylin. The surface epithelium and glands in the stomach, small intestine, cecum, and large intestine were scored blind to treatment for the presence of Muc1 in the apical membrane and cytoplasm. The proportion of cells staining ( 0 , no/weak staining; $1,0-25 \%$ of cells; 2 , $26-50 \% ; 3,51-75 \% ; 4,76-100 \%)$ and the intensity ( 0 , no/weak staining; $1-3$, increasing intensity of staining) were scored. Sections from infected and uninfected $\mathrm{Muc1}^{-/-}$mice were included as controls for staining specificity and scored negatively. C. jejuni was similarly detected using biotinylated NCL-C-JEJUNI anti-flagella antibody (Novocastra Laboratories) and cleaved caspase-3 with a rabbit polyclonal antibody (Calbiochem).

Antibiotic treatment. Reduction of normal flora within the gastrointestinal tract of mice was achieved by oral administration of the broad-spectrum antibiotics vancomycin hydrochloride $(250 \mathrm{mg} / \mathrm{ml})$ and imipinem-cilastatin $(250 \mathrm{mg} / \mathrm{ml})$ (Merck Sharp \& Dohme) in drinking water for 7 days and antibiotic was withdrawn 24 hours prior to inoculation with C. jejuni.

Quantitation of intestinal and fecal bacteria. The entire large intestine, including luminal contents, of $\mathrm{Muc1}^{-/-}$and $\mathrm{Muc1}^{+/+}$mice was homogenized, fixed with $3 \%$ formaldehyde, filtered onto $0.2 \mu \mathrm{m}$ Anodisc 25 - $\mathrm{mm}$ filters (Whatman), and stained with SYBR green (Invitrogen); the number of bacteria was counted under fluorescence microscopy using Image-Pro Plus, version 5.0.0.39 (MediaCybernetics) and expressed per gram of intestinal tissue. DNA was extracted from feces of $\mathrm{Mucl}^{-/-}$and $\mathrm{Mucl}^{+/+}$mice and quantitative PCR used to amplify $16 \mathrm{~S}$ ribosomal DNA from the major intestinal bacterial groups using the following primers: universal 16S DNA (45); Bacteroides-Prevotella-Porphyromonas, Clostridium coccoides and Lactobacillus groups, and Enterococcus spp (46); Clostridium leptum subgroup (47); and Desulfovibrio group (48). Bifidobacterium genus primers were as follows: forward primer, 5'-TTACGTCCAGGGCTTCACG-3'; reverse primer, 5'-ATTACTAGCGACTCCGCCTTCA- $3^{\prime}$. Results were expressed as a proportion of universal bacterial $16 \mathrm{~S}$ ribosomal DNA primers.

Manipulation of MUC1 gene expression in vitro. HCT116 intestinal cancer cells were transfected with a MUC1 cDNA containing 22 VNTR repeats in the pcDNA3 vector (Invitrogen) or the vector alone. Stable G418resistant clones were isolated and MUC1 expression determined by 
flow cytometry. Two differing MUC1 shRNAs (M1.3, 5'-GCACCGACTACTACCAAGATTCAAGAGATCTTGGTAGTAGTCGGTGC-3'; M1.4, 5'-GCAGCCTCTCGATATAACCTTCAAGAGAGGTTATATCGAGAGGCTGC- $3^{\prime}$ ) were cloned into the PSIREN vector and used together with a control (luciferase) shRNA (Clontech; Cambrex). HeLa cervical cancer cells were transfected with pSIREN vectors using Lipofectamine 2000 (Invitrogen) and stable antibiotic-resistant bulk cultures selected by growth for 10 days in $2 \mu \mathrm{g} / \mathrm{ml}$ puromycin. MUC1 expression was determined by flow cytometry with the BC2 antibody (24).

In vitro cocultures. HCT116 cells stably transfected with MUC1 or the pcDNA3 vector were grown in 24-well plate wells in 10\% FCS in RPMI1640 for 5 days after reaching confluence and transferred to microaerophilic gas $\left(5 \% \mathrm{O}_{2}, 15 \% \mathrm{CO}_{2}, 80 \% \mathrm{~N}_{2}\right)$ for 2 hours at $37^{\circ} \mathrm{C}$ prior to the introduction of C. jejuni prepared as above. After 1 or 2 hours, monolayers were washed twice with PBS and lysed with $0.02 \%$ Triton X-100 in PBS; CFUs were determined as above. To measure invasion, after washing, monolayers were cultured in fresh medium with $400 \mu \mathrm{g} / \mathrm{ml}$ gentamicin for a further 2 hours at $37^{\circ} \mathrm{C}$ under microaerophilic conditions and then harvested and CFUs determined.

Assessment of cell-cycle arrest and apoptosis. HCT116 and HeLa cells were established as monolayer cultures in 24-well plates at densities of 2 to $5 \times 10^{4}$ cells/well 1-2 days prior to being exposed to a range of concentrations of CDT for 1-7 days and then harvested with trypsin and combined with any nonadherent cells. For cell-cycle analysis, cells were fixed for 24 hours in $70 \%$ ethanol, stained with 7-amino-actinomycin D (7-AAD), assessed by flow cytometry, and analyzed using the Cylchred, (version 1.0.2; http:// www.cardiff.ac.uk/medicine/haematology/cytonetuk/documents/software.htm). For assessment of apoptosis, harvested cells were stained with annexin V-PE (BD) and 7-AAD and analyzed by flow cytometry for cells in early (annexin $\mathrm{V}$ positive, 7-AAD negative) and late (annexin $\mathrm{V}$ and 7-AAD positive) apoptosis. Cell-cycle dynamics in CDT-affected HCT116 cells could not be assessed by flow cytometry due to the distension and clumping of arrested cells; therefore cells were harvested and manually counted using a hemocytometer. Activity of activated caspases 3 and 7 was determined in intestinal extracts using a modification (49) of the Caspase-Glo 3/7 luminescence assay (Promega).
Confocal microscopy. HeLa and transfected HCT116 cells were grown on coverslips, exposed to CDT for 1-24 hours, fixed with $4 \%$ paraformaldehyde in PBS, permeabilized with $0.1 \%$ Triton X-100, and stained with the MUC1 extracellular domain antibody BC2, the MUC1 cytoplasmic domain antibody CT2, and/or the D07 p53 antibody (Dako) and DAPI (Invitrogen), and examined with an LSM 510 META confocal microscope (Zeiss).

Statistics. CFU data were log transformed and the normality of distribution assessed using probability plots. If a normal distribution was ascertained, then means were compared using ANOVA and Tukey's post-hoc test. If a normal distribution could not be ascertained, then nonparametric tests were utilized (Mann-Whitney $U$ test) to compare means. All analyses were conducted using Systat, version 10.2 (Systat). $P$ values less than 0.05 were considered significant.

\section{Acknowledgments}

This research was supported by Australian National Health and Medical Research Council project grants 235608 and 382309. J.L. McAuley was supported by an Australian Postgraduate Award, S.K. Linden by a Wenner-Gren postdoctoral fellowship, and M.A. McGuckin by a Queensland Cancer Fund senior research fellowship. Our thanks are extended to Jim Fox for supply of the $\triangle \mathrm{CDT}-\mathrm{B}$ C. jejuni, Ann-Marie Burns and Deborah Roche for their care of the animals used in this research, and Vanessa Rowe for assistance with bone marrow transplantation.

Received for publication August 26, 2005, and accepted in revised form May 8, 2007.

Address correspondence to: Michael A. McGuckin, Mucosal Diseases Program, Mater Medical Research Institute, Level 3 Aubigny Place, Mater Hospitals, South Brisbane, Queensland 4101, Australia. Phone: 61-7-3840-2568; Fax: 61-7-3840-2550; E-mail: mmcguckin@ mmri.mater.org.au.

Julie L. McAuley's present address is: Department of Infectious Diseases, St. Jude Children's Research Hospital, Memphis, Tennessee, USA.
1. Dekker, J., Rossen, J.W., Buller, H.A., and Einerhand, A.W. 2002. The MUC family: an obituary. Trends Biochem. Sci. 27:126-131.

2. Linden, S., et al. 2002. Strain- and blood groupdependent binding of Helicobacter pylori to human gastric MUC5AC glycoforms. Gastroenterology. 123:1923-1930.

3. Mukherjee, P., Tinder, T.L., Basu, G.D., and Gendler, S.J. 2005. MUC1 (CD227) interacts with lck tyrosine kinase in Jurkat lymphoma cells and normal T cells. J. Lenkoc. Biol. 77:90-99.

4. Lillehoj, E.P., Kim, H., Chun, E.Y., and Kim, K.C. 2004. Pseudomonas aeruginosa stimulates phosphorylation of the airway epithelial membrane glycoprotein Muc1 and activates MAP kinase. Am. J. Physiol. Lung Cell. Mol. Physiol. 287:L809-L815.

5. Wang, H., Lillehoj, E.P., and Kim, K.C. 2004. MUC1 tyrosine phosphorylation activates the extracellular signal-regulated kinase. Biochem. Biophys. Res. Commun. 321:448-454.

6. Rahn, J.J., Shen, Q., Mah, B.K., and Hugh, J.C. 2004. MUC1 initiates a calcium signal after ligation by intercellular adhesion molecule-1. J. Biol. Chem. 279:29386-29390.

7. Meerzaman, D., Shapiro, P.S., and Kim, K.C. 2001. Involvement of the MAP kinase ERK2 in MUC1 mucin signaling. Am. J. Physiol. Lung Cell. Mol. Physiol. 281:L86-L91.

8. Gendler, S.J. 2001. MUC1, the renaissance molecule. J. Mammary Gland Biol. Neoplasia. 6:339-353.
9. Walters, R.W.,Pilewski,J.M., Chiorini,J.A., andZabner, J. 2002. Secreted and transmembrane mucins inhibit gene transfer with AAV4 more efficiently than AAV5. J. Biol. Chem. 277:23709-23713.

10. Arcasoy, S.M., et al. 1997. MUC1 and other sialoglycoconjugates inhibit adenovirus mediated gene transfer to epithelial cells. Am. J. Respir. Cell Mol. Biol. 17:422-435.

11. Kardon, R., et al. 1999. Bacterial conjunctivitis in Muc1 null mice. Invest. Ophthalmol. Vis. Sci. 40:1328-1335.

12. DeSouza, M.M., et al. 1999. MUC1/episialin: a critical barrier in the female reproductive tract. J. Reprod. Immunol. 45:127-158.

13. Schroeder, J.A., Thompson, M.C., Gardner, M.M., and Gendler, S.J. 2001. Transgenic MUC1 interacts with epidermal growth factor receptor and correlates with mitogen-activated protein kinase activation in the mouse mammary gland. J. Biol. Chem. 276:13057-13064.

14. Raina, D., Kharbanda, S., and Kufe, D. 2004 The MUC1 oncoprotein activates the anti-apoptotic phosphoinositide 3-kinase/Akt and Bcl-xL pathways in rat 3 Y 1 fibroblasts. J. Biol. Chem. 279:20607-20612.

15. Wei, X., Xu, H., and Kufe, D. 2005. Human MUC1 oncoprotein regulates $\mathrm{p} 53$-responsive gene transcription in the genotoxic stress response. Cancer Cell. 7:167-178.

16. Ren, J., et al. 2004. Human MUC1 carcinoma-asso- ciated protein confers resistance to genotoxic anticancer agents. Cancer Cell. 5:163-175.

17. Hugdahl, M.B., Beery, J.T., and Doyle, M.P. 1988. Chemotactic behavior of Campylobacter jejuni. Infect. Immun. 56:1560-1566.

18. Ruiz-Palacios, G.M., Cervantes, L.E., Ramos, P., Chavez-Munguia, B., and Newburg, D.S. 2003. Campylobacter jejuni binds intestinal $\mathrm{H}(\mathrm{O})$ antigen (Fuc alpha 1, 2Gal beta 1, 4GlcNAc), and fucosyloligosaccharides of human milk inhibit its binding and infection. J. Biol. Chem. 278:14112-14120.

19. Linden, S.K., Driessen, K.M., and McGuckin, M.A. 2007. Improved in vitro model systems for gastrointestinal infection by choice of cell line, $\mathrm{pH}$, microaerobic conditions and optimization of culture conditions. Helicobacter. In press.

20. Jang, M.H., et al. 2004. Intestinal villous M cells: an antigen entry site in the mucosal epithelium. Proc. Natl. Acad. Sci. U. S. A. 101:6110-6115.

21. Lelouard, H., et al. 2001. Glycocalyx on rabbit intestinal $\mathrm{M}$ cells displays carbohydrate epitopes from Muc2. Infect. Immun. 69:1061-1071.

22. Brugger, W., et al. 1999. Expression of MUC-1 epitopes on normal bone marrow: implications for the detection of micrometastatic tumor cells. J. Clin. Oncol. 17:1535-1544.

23. Agrawal, B., Krantz, M.J., Parker, J., and Longenecker, B.M. 1998. Expression of MUC1 mucin on activated human $\mathrm{T}$ cells: implications for a role of MUC1 in normal immune regulation. Cancer Res. 
58:4079-4081.

24. Wykes, M., et al. 2002. MUC1 epithelial mucin (CD227) is expressed by activated dendritic cells J. Lenkoc. Biol. 72:692-701.

25. Dent, G.A., Civalier, C.J., Brecher, M.E., and Bentley, S.A. 1999. MUC1 expression in hematopoietic tissues. Am. J. Clin. Pathol. 111:741-747.

26. Li, Q., Ren, J., and Kufe, D. 2004. Interaction of human MUC1 and beta-catenin is regulated by Lck and ZAP-70 in activated Jurkat T cells. Biochem. Biophys. Res. Commun. 315:471-476.

27. Agrawal, B., and Longenecker, B.M. 2005. MUC1 mucin-mediated regulation of human $\mathrm{T}$ cells. Int. Immunol. 17:391-399.

28. Fauchere, J.L., Veron, M., Lellouch-Tubiana, A., and Pfister, A. 1985. Experimental infection of gnotobiotic mice with Campylobacter jejuni: colonisation of intestine and spread to lymphoid and reticuloendothelial organs. J. Med. Microbiol. 20:215-224.

29. Field, L.H., Underwood, J.L., and Berry, L.J. 1984. The role of gut flora and animal passage in the colonisation of adult mice with Campylobacter jejuni. J. Med. Microbiol. 17:59-66.

30. Lara-Tejero, M., and Galan, J.E. 2000. A bacterial toxin that controls cell cycle progression as a deoxyribonuclease I-like protein. Science. 290:354-357.

31. Purdy, D., et al. 2000. Characterisation of cytolethal distending toxin (CDT) mutants of Campylobacter jejuni. J. Med. Microbiol. 49:473-479.

32. Scheffner, M., Werness, B.A., Huibregtse, J.M., Levine, A.J., and Howley, P.M. 1990. The E6 oncoprotein encoded by human papillomavirus types 16 and 18 promotes the degradation of p53. Cell.
63:1129-1136.

33. Fox, J.G., et al. 2004. Gastroenteritis in NF-kappaB-deficient mice is produced with wild-type Camplyobacter jejuni but not with C. jejuni lacking cytolethal distending toxin despite persistent colonization with both strains. Infect. Immun. 72:1116-1125.

34. Carvalho, F., et al. 1997. MUC1 gene polymorphism and gastric cancer - an epidemiological study. Glycoconj. J. 14:107-111.

35. Silva, F., et al. 2001. MUC1 gene polymorphism in the gastric carcinogenesis pathway. Eur. J. Hum. Genet. 9:548-552.

36. Vinall, L.E., et al. 2002. Altered expression and allelic association of the hypervariable membrane mucin MUC1 in Helicobacter pylori gastritis. Gastroenterology. 123:41-49.

37. Silva, F., et al. 2003. MUC1 polymorphism confers increased risk for intestinal metaplasia in a Colombian population with chronic gastritis. Eur. J. Hum. Genet. 11:380-384.

38. Bramwell, M.E., Wiseman, G., and Shotton, D.M. 1986. Electron-microscopic studies of the CA antigen, epitectin. J. Cell Sci. 86:249-261.

39. Wreschner, D.H., et al. 2002. Generation of ligandreceptor alliances by "SEA" module-mediated cleavage of membrane-associated mucin proteins. Protein Sci. 11:698-706.

40. Thathiah, A., Blobel, C.P., and Carson, D.D. 2003. Tumor necrosis factor-alpha converting enzyme/ ADAM 17 mediates MUC1 shedding. J. Biol. Chem. 278:3386-3394.

41. Thathiah, A., and Carson, D.D. 2004. MT1-MMP mediates MUC1 shedding independent of TACE/ ADAM17. Biochem. J. 382:363-373.

42. Winterford, C.M., Walsh, M.D., Leggett, B.A., and Jass, J.R. 1999. Ultrastructural localization of epithelial mucin core proteins in colorectal tissues. J. Histochem. Cytochem. 47:1063-1074.

43. Spicer, A.P., Rowse, G.J., Lidner, T.K., and Gendler, S.J. 1995. Delayed mammary tumor progression in Muc-1 null mice. J. Biol. Chem. 270:30093-30101.

44. Thornton, D.J., Khan, N., and Sheehan, J.K. 2000. Separation and identification of mucins and their glycoforms. Methods Mol. Biol. 125:77-85.

45. Rupf, S., Merte, K., and Eschrich, K. 1999. Quantification of bacteria in oral samples by competitive polymerase chain reaction. J. Dent. Res. 78:850-856.

46. Rinttila, T., Kassinen, A., Malinen, E., Krogius, L., and Palva, A. 2004. Development of an extensive set of $16 \mathrm{~S}$ rDNA-targeted primers for quantification of pathogenic and indigenous bacteria in faecal samples by real-time PCR. J. Appl. Microbiol. 97:1166-1177.

47. Matsuki, T., Watanabe, K., Fujimoto, J., Takada, T., and Tanaka, R. 2004. Use of 16S rRNA genetargeted group-specific primers for real-time PCR analysis of predominant bacteria in human feces. Appl. Environ. Microbiol. 70:7220-7228.

48. Fite, A., et al. 2004. Identification and quantitation of mucosal and faecal desulfovibrios using real time polymerase chain reaction. Gut. 53:523-529.

49. Liu, D., et al. 2004. Nuclear import of proinflammatory transcription factors is required for massive liver apoptosis induced by bacterial lipopolysaccharide. J. Biol. Chem. 279:48434-48442. 